\title{
Whole genome sequence based capsular typing and antimicrobial resistance prediction of Group B streptococcal isolates from colonized pregnant women in Nigeria
}

Mienye Bob-Manuel ${ }^{1}$, Lesley McGee ${ }^{2 *}$, Jeremiah A Igunma ${ }^{3}$, Mary A Alex-Wele ${ }^{4}$, Orikomaba K Obunge ${ }^{4}$ and Kennedy T Wariso $^{4}$

\begin{abstract}
Background: Streptococcus agalactiae (Group B Streptococcus, GBS) is one of the major bacterial pathogens responsible for neonatal sepsis. Whole genome sequencing has, in recent years, emerged as a reliable tool for capsular typing and antimicrobial resistance prediction. This study characterized vaginal and rectal isolates of Group B Streptococcus obtained from pregnant women in Port Harcourt, Nigeria using a whole-genome sequence-based approach.

Results: Capsular types la, Ib, II, III, IV and V were detected among the 43 isolates sequenced. Twelve sequence types (STs) were identified, with ST19 $(n=9,27.3 \%)$ and ST486 $(n=5,15.2 \%)$ the most frequent among non-duplicated isolates. Of the alpha-like proteins (alp) identified, Alp1 was the most prevalent in 11 (33.3\%) isolates. Macrolide and lincosamide resistance determinants were present in 15 (45.5\%) isolates; ermB was detected in $1(3 \%)$, ermTR in $7(21.2 \%)$ isolates, Inu gene was detected in $6(18.2 \%)$ and mef was identified in $3(9.1 \%)$ isolates. Resistance of GBS to erythromycin and clindamycin (predicted from presence of erm or mef genes) was found to be $30.3 \%$ and $24.2 \%$, respectively. All isolates were predicted resistant to tetracycline with only the tetM gene identified. Fluoroquinolone-resistance conferring substitutions in gyrA+ parc were detected in $9(27.3 \%)$ isolates and chloramphenicol resistance was predicted from presence of aac6'-aph2 gene in 11 (33.3\%).

Conclusions: The data available from the whole genome sequencing of these isolates offers a small but insightful description of common serotypes and resistance features within colonizing GBS in Nigeria.
\end{abstract}

Keywords: Whole genome sequencing, Group B Streptococcus, Nigeria, capsular typing, Antimicrobial resistance

\footnotetext{
* Correspondence: Imcgee@cdc.gov

${ }^{2}$ Respiratory Diseases Branch, Centers for Disease Control and Prevention, 1600 Clifton Rd, GA 30329 Atlanta, USA

Full list of author information is available at the end of the article
}

C C The Author(s). 2021 Open Access This article is licensed under a Creative Commons Attribution 4.0 International License, which permits use, sharing, adaptation, distribution and reproduction in any medium or format, as long as you give appropriate credit to the original author(s) and the source, provide a link to the Creative Commons licence, and indicate if changes were made. The images or other third party material in this article are included in the article's Creative Commons licence, unless indicated otherwise in a credit line to the material. If material is not included in the article's Creative Commons licence and your intended use is not permitted by statutory regulation or exceeds the permitted use, you will need to obtain permission directly from the copyright holder. To view a copy of this licence, visit http://creativecommons.org/licenses/by/4.0/. The Creative Commons Public Domain Dedication waiver (http://creativecommons.org/publicdomain/zero/1.0/) applies to the data made available in this article, unless otherwise stated in a credit line to the data. 


\section{Introduction}

Streptococcus agalactiae, also known as Group B Streptococcus (GBS) is increasingly being recognized in Africa as one of the major pathogens responsible for neonatal sepsis [1-3]. Vertical transmission from a rectovaginally colonized mother is the main predisposing factor for the development of early onset neonatal GBS sepsis $[4,5]$. Some countries, including the United States and Australia, have policies regarding intrapartum antibiotic prophylaxis (IAP) to prevent early-onset disease (EOD) with resulting benefits [6, 7]. However, many low and middle income countries are yet to develop or implement such policies [8]. Whilst vaccine development is still underway $[9,10]$, IAP remains one of the most effective tools for the prevention of $\operatorname{EOD}[7,11]$. The use of IAP may inadvertently result in the increase of antimicrobial resistance (AMR) [8]. For this reason, determination of antimicrobial resistance patterns is important, especially in settings such as Nigeria where there is high incidence of indiscriminate antibiotic use [12]. Whole genome sequencing (WGS) has emerged as a reliable and cost-effective method for capsular typing and for accurate predictions of minimum inhibitory concentrations for antimicrobials in GBS [13-15].

This study analysed whole genome sequences of colonizing Group B Streptococcus isolates from vaginal and rectal swabs obtained from a previously described study in pregnant women in Port Harcourt, Nigeria [16]. Data from this study will add to existing evidence to guide vaccine efforts as well as contribute to local recommendations for intrapartum antibiotic prophylaxis.

\section{Materials and methods}

\section{Bacterial isolates}

A total of 46 GBS isolates, obtained from separate vaginal and rectal samples of 185 pregnant women in their third trimester, collected retrospectively between March and July 2018 were used in this study. Samples were collected from women receiving antenatal care at the University of Port Harcourt Teaching Hospital in Port Harcourt Nigeria. Ethical approval was received from the hospital's ethics board and each participant signed a consent form prior to enrolment. Details of the study design and sample collection are described previously by Bob-Manuel et al. [16]. Briefly, the rectovaginal samples were incubated overnight in LIM RambaQUICK ${ }^{\mathrm{TM}}$ (CHROMagar, France) and subcultured onto CHROMagar ${ }^{\mathrm{TM}}$ StrepB (CHROMagar, France). Streptococcus agalactiae were presumptively identified as small, mauve-coloured colonies on CHROMagar StrepB. Isolates were stored in tryptic soy broth containing $5 \%$ glycerol at $-70{ }^{\circ} \mathrm{C}$. The isolates were shipped on Columbia agar with chocolated horse blood (Oxoid, UK) to the Streptococcus Laboratory, Centers for Disease Control and Prevention (CDC), for whole genome sequencing.
Whole genome sequencing and strain feature prediction At CDC, GBS isolates were cultured on Trypticase soy agar supplemented with $5 \%$ sheep blood prior to DNA extraction from single colonies as previously described [13]. Following shearing of samples using a Covaris M220 ultrasonicator (Covaris, Inc, MA, USA) genomic libraries were constructed using sparQ DNA Library Kit (Quantabio, MA USA) [13, 14]. Short read sequences were generated on Illumina Miseq platform with MiSeq v2 500 cycle kit (Illumina Inc, USA) and assembled de novo using VelvetOptimiser [17]. Serotypes, multilocus sequence typing (MLST), antibiotic resistance determinants, and predicted minimum inhibitory concentrations (MICs) were determined using a previously validated GBS bioinformatics pipeline [13]. Isolates flagged for phenotypic testing (those with $\ln u$ gene and $e r m \mathrm{TR}+\ln u$ ) were tested by Etest (Biomerieux USA) using Mueller-Hinton agar with $5 \%$ sheep blood (Becton Dickinson, USA), according to manufacturer's instructions. Interpretation of susceptible, intermediate and resistant from MIC WGS-prediction and Etest were determined using the standard Clinical Laboratory Standards Institute (CLSI) breakpoints for beta-hemolytic streptococci [18]. Additional strain features, including surface protein genes encoding the hypervirulent GBS adhesin ( $h v g a)$, serine-rich repeat (srr) proteins, alpha protein family (alpha, Rib, Alp2/3, Alp1), and pilus proteins predictive of pilus islands (designated here as PI1, PI2A, and PI2B) were extracted from genomic data (https:// github.com/BenJamesMetcalf) [14]. Isolate identifiers, pipeline features, antimicrobial MIC predictions and interpretations, assembly metrics and NCBI genome accession numbers are listed in Supplementary Table 1. Contingency tables and a $\chi^{2}$ test (or Fisher's exact test) were used to determine the significance of associations (at $\alpha=0.05$ ).

\section{Results}

The proportion of vaginal/rectal samples positive for GBS was $16.8 \%$ (31/185 women) (sTable 1$) ; 12$ women had both vaginal and rectal swabs positive for GBS with 10 women having identical serotypes and therefore counted only once in further analyses. Whole genome sequencing revealed 3 of the isolates to be non-GBS. Six of ten known capsular serotypes (Ia, Ib, II, III, IV and V) were detected within this sampling, with serotype $\mathrm{V}$ the most frequent ( $n=11 / 33,33.3 \%$ ) (Table 1). Multilocus sequence typing (MLST) identified a total of 12 STs among the 33 strains with ST19 $(n=9,27.3 \%)$ and ST486 $(n=5,15.2 \%)$ most frequently occurring. Eight (88.9\%) of the ST19 sequence strains were serotype $\mathrm{V}$ isolates while serotype III accounted for 1 (11.1\%) isolate. Only 1 serotype III isolate (3\%) had the highly virulent ST17 clonal type.

The most predominant alpha-protein-like (alp) family present was Alp1 in 11 (33.3\%) isolates, followed by Rib with 9 (27.3\%), Alp2/3 with $6(18.23 \%)$ isolates and 5 
Table 1 Distribution of sequence types (ST) by serotype for 33 non-duplicate GBS isolates

\begin{tabular}{|c|c|c|c|c|c|c|}
\hline \multirow[t]{2}{*}{ ST } & \multicolumn{6}{|c|}{ Serotypes (\%) } \\
\hline & la & Ib & II & III & IV & V \\
\hline 1 & - & - & - & - & - & $1(9.1)$ \\
\hline 2 & - & - & - & - & $2(100.0)$ & - \\
\hline 8 & - & $1(100)$ & - & - & - & - \\
\hline 17 & - & - & - & $1(14.3)$ & - & - \\
\hline 19 & - & - & - & $1(14.3)$ & - & $8(72.7)$ \\
\hline 23 & $1(16.7)$ & - & - & - & - & - \\
\hline 24 & $4(66.7)$ & - & - & - & - & - \\
\hline 26 & - & - & - & - & - & $1(9.1)$ \\
\hline 28 & - & - & $2(33.3)$ & - & - & $1(9.1)$ \\
\hline 182 & - & - & - & $3(42.9)$ & - & - \\
\hline 486 & $1(16.7)$ & - & $4(66.7)$ & - & - & - \\
\hline 1336 & - & - & - & $2(28.6)$ & - & - \\
\hline Total & $6(18.2)$ & $1(3.0)$ & $6(18.2)$ & $7(21.2)$ & $2(6.1)$ & $11(33.3)$ \\
\hline
\end{tabular}

(15.2\%) isolates were Alpha. Rib was detected in capsular types III $(85.7 \%)(p<0.001)$, II $(33.3 \%)$ and V (9.1\%); alp2/3 was detected in II $(66.7 \%)(p=0.002)$, Ia $(16.7 \%)$ and V (9.1\%); alp 1 in Ia (16.7\%), IV (100\%) and $\mathrm{V}(72.7 \%)(p<0.001)$ while the Alpha protein was detected in type Ia $(66.7 \%)(p<0.001)$ and Ib $(100 \%)$ alone. Two isolates were negative for any of the alphaprotein-like family target predictions.

Serine-rich repeat proteins SSR1 and SSR2 were predicted in $29(87.9 \%)$ and 1 (3\%) of the isolates, while 3 $(9.1 \%)$ were negative for both. Only one isolate demonstrated $h v g A$, a serotype III ST17 isolate as expected, the same isolate that was SSR2 positive. Isolates either had 1 or 2 pili; PI1 + PI2A detected in 19 (57.6\%), PI1 + PI2B in $8(24.2 \%)$ and PI2A in $6(18.1 \%)$ isolates. Serotype V isolates mostly contain both PI1 + PI2A $(90.9 \%)(p=0.003)$, serotype II had both PI1 + PI2B (66.7\%) $(p=0.01)$ and serotype $1 \mathrm{~A}$, pilus P2A $(83.3 \%)(P<0.001)$.

Table 2 shows the antibiotic susceptibility as predicted by WGS and detection of specific resistance determinants. Macrolide and clindamycin resistance determinants (erm, $m e f / m s r D$ and $l n u)$ were present in $15(45.5 \%)$ of the isolates with resistance rates to erythromycin and clindamycin of 30.3 and $24.2 \%$, respectively. These determinants

Table 2 Whole Genome Sequencing predicted antibiotic susceptibility for 33 non-duplicate GBS isolates (See Supplemental Table 1 for MIC prediction values)

\begin{tabular}{llll}
\hline Antibiotic & Targeted genes & Susceptible (\%) & Non-Susceptible *(\%) \\
\hline Ampicillin & pbp2X & $33(100)$ & - \\
Ceftriaxone & $p b p 2 X$ & $33(100)$ & - \\
Chloramphenicol & $c a t$ & $25(75.6)$ & $8(24.2)$ \\
Clindamycin & $e r m$ & $25(75.6)$ & $8(24.2)$ \\
Ceftaroline & $p b p 2 X$ & $33(100)$ & - \\
Erythromycin & erm or mef & $23(69.7)$ & $10(30.3)$ \\
Levofloxacin & parC, gyrA & $24(72.7)$ & $9(27.3)$ \\
Meropenem & $p b p 2 X$ & $33(100)$ & - \\
Linezolid & 23 S rRNA & $33(100)$ & - \\
Penicillin & pbp2X & $33(100)$ & - \\
Synercid** & erm + Isa & $33(100)$ & - \\
Cefotaxime & $p b p 2 X$ & $33(100)$ & - \\
Tetracycline & tet & - & $33(100)$ \\
Vancomycin & van & $33(100)$ & - \\
\hline
\end{tabular}

** Quinupristin/Dalfopristin

*Non-susceptibility includes both intermediate and resistant prediction 
were present only in serotypes III (71.4\%), IV (100\%) and $\mathrm{V}$ (72.7\%). The $\mathrm{MLS}_{\mathrm{B}}$ genes which confer resistance to macrolides, lincosamides and streptogramin $\mathrm{B}$, ermB was detected in $1(3.0 \%)$ isolates and ermTR in 7 (21.2 \%) isolates; lincosamide nucleotidyltransferase determinant, lnu, was present in $6(18.2 \%)$ and the determinant for macrolide efflux, mef was detected in $3(9.1 \%)$ isolates. The 5 $(15.2 \%)$ isolates with $\ln u$ alone and the one isolate with erm $\mathrm{TR}+\ln u$ were susceptible to erythromycin + clindamycin and synercid, respectively, when tested phenotypically by Etest. Isolates with $m e f / m s r D$ alone $(2 ; 6.1 \%)$ were predicted as resistant to erythromycin but sensitive to clindamycin.

All isolates were resistant to tetracycline and the only gene detected conferring resistance was tetM. Fluoroquinolone-resistance conferring substitutions in both gyrA (S81L) and $\operatorname{parC}(\mathrm{S} 79 \mathrm{~F})$ were present in 9 $(27.3 \%)$ isolates conferring full resistance phenotype, 8 $(88.9 \%)$ of which were ST19 strains $(p<0.0001)$. Also, all of the isolates with fluoroquinolone resistance determinants were serotype V $(81.1 \%) \quad(p<0.0001)$. The aac6'-aph2 gene, which encodes the bifunctional aminoglycoside-inactivating enzyme with 6'-acetyltransferase and 2"-phosphotransferase activities, were detected in $11(33.3 \%)$ isolates and were exclusively in serotypes III, IV and V: 4 (36.4\%), 1 (9.1\%) and 6 $(54.5 \%)$, respectively. CAT genes, encoding chloramphenicol acetyltransferases, were detected in $8(24.2 \%)$ isolates, among serotypes III $(p=0.02)$, IV and V.

\section{Discussion}

This study reports the molecular characterization of colonizing strains of Group B Streptococcus in the vagina and rectum of pregnant women. Serotype V was the most frequent serotype in this population representing $33.3 \%$ of the population.

Sequence types ST19, 486, 182, 24 and 2 accounted for $69.7 \%$ of the total isolates. This diversity is different from other reports that have reported ST19, ST23 and ST1 more commonly [19]. The highly virulent ST17 responsible for most invasive disease, especially late onset disease in neonates [20], was rare in this study (3\%) population which may suggest a better prognosis for neonates who may become colonized at birth in this environment. While ST182 was reported as a frequent clonal type by Medugu et al. in another local study in Abuja, Nigeria [2], ST486 has not previously been documented as a common sequence type among GBS isolates in Nigeria. The pubMLST [21] (http://pubmlst.org accessed June 10, 2021) and BacWGSTdb 2.0 [22] (bacdbcn/ BacWGSTdb/ accessed June 10th, 2021) show ST182 (Kenya, Malawi and Central African Republic), ST486 (Kenya), ST24 (Kenya and Malawi) and ST2 (Kenya and Ethiopia) from several African countries mainly associated with carriage samples collected during 2006 to 2015, indicating circulation of these less common STs.

Alp1 (Epsilon) (33.3\%) was the most common of all the alpha-like proteins among the isolates in this study, similar to findings reported in Egypt (27\%) [23]. Other studies have documented Rib as the most frequently detected Alp gene in other geographic regions like China and Iran (37.5 and $53 \%$ respectively) [24, 25]. The serine-rich repeat protein Srr-1 was identified in almost all isolates, however only a single isolate had the Srr-2 known to be associated with greater binding affinity and higher morbidity [26]. The same isolate was positive for the hypervirulent GBS adhesin (HvgA), another surface protein demonstrated to increase adhesion and virulence particularly in the ST17 lineage [27].

Similar to other studies from Nigeria [2, 28], all isolates were determined to be susceptible to beta-lactam antibiotics including 3rd generation cephalosporins. This is quite reassuring, suggesting that penicillin and ampicillin remain as viable options for intrapartum antibiotic prophylaxis in this region despite concerns for antimicrobial resistance. For women allergic to penicillin and at high risk of anaphylaxis, guidelines recommend clindamycin as an alternative option for prophylaxis [29]. In this study however, clindamycin and erythromycin resistance were relatively high at 24.2 and $30.3 \%$, respectively. Data from an earlier study in Nigeria reported erythromycin and clindamycin resistance rates of $6.5 \%$ [28] suggesting increased resistance rates within the country. However, all isolates were susceptible to vancomycin in this study, so patients with a high risk for penicillin anaphylaxis who are colonized with a clindamycin resistant GBS strain, could receive vancomycin as the next best option [29].

Although other antibiotic classes such as fluoroquinolones, chloramphenicol, and tetracycline are not recommended for intrapartum prophylaxis, determining their susceptibility is important for tracking of resistance among GBS in general and as useful options for other invasive group B streptococcal infections in other age groups. All isolates were predicted as tetracycline resistant which is consistent with several other reports documenting high levels of resistance to this antibiotic [28, 30, 31]. Resistance to chloramphenicol and levofloxacin were also high at $25.6 \%$. Similarly, while these antibiotics may not be recommended for neonatal sepsis, they may be useful options for other invasive group B streptococcal infections in other age groups.

The only tetracycline gene present in this population was tetM. Of all the tetracycline resistance determinants, the tet $\mathrm{M}$ has the most spread geographically among GBS $[28,30,31]$. The presence of the double gyrA + parC mutants conferring full fluoroquinolone-resistance was 
high and were found predominantly in serotype V/ST19 clone. The most frequently reported fluoroquinolone non-susceptible serotype/ST combinations are III/ST-19 and V/ST-19 [32, 33] supporting the data from this study. Occurrence of either of these clonal complexes is likely a reflection of the circulating clones in those geographical areas in which they are found.

This study has demonstrated some salient characteristics of the prevalent colonizing strains of GBS in Nigeria, thus, contributing to the body of knowledge concerning GBS, as well as providing AMR data if IAP is considered in the future.

\section{Supplementary information}

The online version contains supplementary material available at https://doi. org/10.1186/s12864-021-07929-z.

\section{Additional file 1}

\section{Acknowledgements}

Sincere thanks to Bernard Beall, Chief Streptococcus Laboratory, Centers for Disease control and Prevention and his entire team for their willingness to assist and making this strain characterization study possible.

The findings and conclusions in this report are those of the authors and do not necessarily represent the official position of the Centers for Disease Control and Prevention.

\section{Authors' contributions}

Authors MB and LM conceived and designed the study. LM coordinated the whole genome sequencing and analyses. MB wrote most of the manuscript with major review and editing by LM. JI and MA helped with the data analysis. $\mathrm{OO}$ and $\mathrm{KW}$ contributed to critically reviewing the manuscript. All authors read and approved the final manuscript.

\section{Funding}

Funding for whole genome sequencing was provided by CDC through Advanced Microbial Detection Project FY21-AMD-161.

\section{Availability of data and materials}

Genome sequences has been uploaded to GenBank https://www.ncbi.nlm. nih.gov/sra/PRJNA632041. See sTable 1 for BioSample Accession numbers (SAMN18352391- SAMN18352411).

\section{Declarations}

\section{Ethics approval and consent to participate}

Ethical approval for the study was obtained from the University of Port Harcourt Teaching Hospital Ethical Committee (UPTH/ADM/90/S. IINOL.XI/ 369). Written informed consent was obtained from each participant prior to study enrolment. All methods were carried out in accordance with relevant guidelines and regulations.

\section{Consent for publication}

Not applicable.

\section{Competing interests}

The authors declare that they have no competing interests.

\section{Author details}

${ }^{1}$ Department of Medical Microbiology and Parasitology, Rivers State University Teaching Hospital, Port Harcourt, Nigeria. ${ }^{2}$ Respiratory Diseases Branch, Centers for Disease Control and Prevention, 1600 Clifton Rd, GA 30329 Atlanta, USA. ${ }^{3}$ Department of Medical Microbiology, University of Benin Teaching Hospital, Benin City, Nigeria. ${ }^{4}$ Department of Medical Microbiology and Parasitology, University of Port Harcourt Teaching Hospital, Port Harcourt, Nigeria.
Received: 5 April 2021 Accepted: 5 August 2021

Published online: 23 August 2021

\section{References}

1. Yadeta TA, Worku A, Egata G, Seyoum B, Marami D, Berhane Y. Vertical transmission of group $B$ streptococcus and associated factors among pregnant women: A cross-sectional study, Eastern Ethiopia. Infect Drug Resist. 2018;11:397-404. https://doi.org/10.2147//DR.S150029.

2. Medugu N, Iregbu KC, Parker RE, Plemmons J, Singh P, Audu LI, et al. Group B streptococcal colonization and transmission dynamics in pregnant women and their newborns in Nigeria: implications for prevention strategies. Clin Microbiol Infect. 2017;23(9):673.e9-673.e16. https://doi.org/1 0.1016/j.cmi.2017.02.029. Accessed 22 Mar 2018.

3. Sinha A, Russell LB, Tomczyk S, Verani JR, Schrag SJ, Berkley JA, et al. Disease burden of Group B streptococcus among infants in Sub-Saharan Africa. Pediatr Infect Dis J. 2016;35(9): 933-942. https://doi.org/10.1097/INF. 0000000000001233. Accessed 29 Mar 2018.

4. Dangor Z, Lala SG, Cutland CL, Koen A, Jose L, Nakwa F, et al. Burden of invasive group B Streptococcus disease and early neurological sequelae in South African infants. PLoS One. 2015;10(4). https://doi.org/10.1371/journal. pone.0123014. Accessed 29 Mar 2018.

5. Hansen SM, Uldbjerg N, Kilian M, Sørensen UBS. Dynamics of Streptococcus agalactiae Colonization in Women during and after Pregnancy and in Their Infants. J Clin Microbiol. 2004;42(1):83-89. https://doi.org/10.1128/jcm.42.1. 83-89.2004. Accessed 22 Mar 2018.

6. Daley AJ, Isaacs D. Ten-Year Study on the Effect of Intrapartum Antibiotic Prophylaxis on Early Onset Group B Streptococcal and Escherichia coli Neonatal Sepsis in Australasia. Pediatr Infect Dis J. 2004;23(7):630-634. https://doi.org/10.1097/01.inf.0000128782.20060.79. Accessed 01 Apr 2018.

7. Schrag SJ, Verani JR. Intrapartum antibiotic prophylaxis for the prevention of perinatal group B streptococcal disease: Experience in the United States and implications for a potential group B streptococcal vaccine. Vaccine. 2013;31: D20-26. https://doi.org/10.1016/j.vaccine.2012.11.056. Accessed 2 Sept 2018.

8. Le Doare K, O'Driscoll M, Turner K, Seedat F, Russell NJ, Seale AC, et al. Intrapartum Antibiotic Chemoprophylaxis Policies for the Prevention of Group B Streptococcal Disease Worldwide: Systematic Review. Clin Infect Dis. 2017;65(Suppl 2):S143-151. https://doi.org/10.1093/cid/cix654. Accessed 10 Mar 2020.

9. Kobayashi M, Schrag SJ, Alderson MR, Madhi SA, Baker CJ, Sobanjo-ter Meulen A, et al. WHO consultation on group B Streptococcus vaccine development: Report from a meeting held on 27-28 April 2016. Vaccine. 2016;37(50):7307-7314. https://doi.org/10.1016/j.vaccine.2016.12.029. Accessed 27 Feb 2018

10. Lin SM, Zhi Y, Ahn KB, Lim S, Seo HS. Status of group B streptococcal vaccine development. Clin Exp Vaccine Res 2018;7(1):76. https://doi.org/10. 7774/cevr.2018.7.1.76. Accessed 10 Mar 2020.

11. Nishihara Y, Dangor Z, French N, Madhi S, Heyderman R. Challenges in reducing group B Streptococcus disease in African settings. Arch Dis Child. 2017;102(1):72-77. https://doi.org/10.1136/archdischild-2016-311419. Accessed 10 Mar 2020

12. Egwuenu A, Obasanya J, Okeke I, Aboderin O, Olayinka A, Kwange D, et al. Antimicrobial use and resistance in Nigeria: situation analysis and recommendations, 2017. Pan Afr Med J. 2018;8(8):2. https://doi.org/10.11 604/pamj.cp.2018.8.2.701. Accessed 2 Jun 2020.

13. Metcalf BJ, Chochua S, Gertz RE, Hawkins PA, Ricaldi J, Li Z, et al. Shortread whole genome sequencing for determination of antimicrobial resistance mechanisms and capsular serotypes of current invasive Streptococcus agalactiae recovered in the USA. Clin Microbiol Infect. 2017;23(8):574.e7-574.e14. https://doi.org/10.1016/j.cmi.2017.02.021. Accessed 23 Jan 2019.

14. McGee L, Chochua S, Li Z, Mathis S, Rivers J, Metcalf B, et al. Multistate, population-based distributions of candidate vaccine targets, clonal complexes, and resistance features of invasive Group B Streptococci within the US: 2015-2017. Clin Infect Dis. 2020;15:ciaa151. https://doi.org/10.1093/ cid/ciaa151. Accessed 6 Dec 2020.

15. Zankari E, Hasman H, Cosentino S, Vestergaard M, Rasmussen S, Lund O, et al. Identification of acquired antimicrobial resistance genes. J Antimicrob Chemother. 2012;67(11):2640-2644. https://doi.org/10.1093/jac/dks261. Accessed 3 Mar 2020.

16. Bob-Manuel M, Lawson SD, Kasso T, Oboro IL, Obunge OK, Wariso KT. Epidemiology and Capsular Typing of Group B Streptococcus in 
Pregnant Women in Port Harcourt, Nigeria. Annals Microbiol Infect Dis. 2021:4(1):16

17. Zerbino DR, Birney E. Velvet: Algorithms for de novo short read assembly using de Bruijn graphs. Genome Res 2008;18(5):821-9.

18. Clinical Laboratory Standards Institute. 2020. Performance standards for antimicrobial susceptibility testing - approved standard M100-S30, 29th ed. CLSI, Wayne, Pa.

19. Manning SD, Lewis MA, Springman AC, Lehotzky E, Whittam TS, Davies HD. Genotypic diversity and serotype distribution of group B streptococcus isolated from women before and after delivery. Clin Infect Dis. 2008;46(12):1829-1837. https://doi.org/10.1086/588296. Accessed 30 Sept 2020

20. Jones N, Oliver KA, Barry J, Harding RM, Bisharat N, Spratt BG, et al. Enhanced invasiveness of bovine-derived neonatal sequence type 17 group B Streptococcus is independent of capsular serotype. Clin Infect Dis. 2006;42(7):915-924. https://doi.org/10.1086/500324. Accessed 28 Oct 2020.

21. Jolley KA, Bray JE, Maiden MCJ. Open-access bacterial population genomics: BIGSdb software, the PubMLST.org website and their applications. Wellcome Open Res. 2018;3:124.

22. Feng Y, Zou S, Chen H, Yu Y, Ruan Z. BacWGSTdb 2.0: a one-stop repository for bacterial whole-genome sequence typing and source tracking. Nucleic Acids Res. 2021:49(D1):D644-D650.

23. Shabayek S, Abdalla S. Abouzeid A MH. Serotype and surface protein gene distribution of colonizing group $B$ streptococcus in women in Egypt Epidemiol. Infect. 2014;42:208-210. https://doi.org/10.1017/\$0950268813 000848. Accessed 2 Nov 2020.

24. Lu B, Wang D, Zhou H, Zhu F, Li D, Zhang S, et al. Distribution of pilus islands and alpha-like protein genes of group B Streptococcus colonized in pregnant women in Beijing, China. Eur J Clin Microbiol Infect Dis. 2015; 34(6):1173-1179. https://doi.org/10.1007/s10096-015-2342-9. Accessed 20 Mar 2018

25. Sadeh M, Firouzi R, Derakhshandeh A, Bagher Khalili M, Kong F, Kudinha T. Molecular Characterization of Streptococcus agalactiae Isolates From Pregnant and Non-Pregnant Women at Yazd University Hospital, Iran. Jundishapur J Microbiol. 2016;9(2):e30412. https://doi.org/10.5812/jim.30412. Accessed 2 Feb 2018.

26. Armistead B, Oler E, Adams Waldorf K, Rajagopal L. The Double Life of Group B Streptococcus: Asymptomatic Colonizer and Potent Pathogen. J Mol Biol. 2019;431(16):2914-2931. https://doi.org/10.1016/j.jmb.2019.01.035. Accessed 2 Nov 2020.

27. Tazi A, Disson O, Bellais S, Bouaboud A, Dmytruk N, Dramsi S, Mistou MY, et al. The surface protein HvgA mediates group B streptococcus hypervirulence and meningeal tropism in neonates. J Exp Med 2010;207(11): 2313-2322. https://doi.org/10.1084/jem.20092594. Accessed 30 Sept 2020.

28. Elikwu CJ, Oduyebo O, König B. Antibiotic susceptibility profiles of group $B$ streptococci (GBS) isolates from pregnant mothers in a tertiary institution in Nigeria. Int J Infect Dis. 2014;21:348. https://doi.org/10.41 03/2468-6859.185250. Accessed 25 Feb 2018.

29. Prevention of Group B Streptococcal Early-Onset Disease in Newborns: ACOG Committee Opinion, Number 797. Obstet Gynecol. 2020;135(2):e51e72. https://doi.org/10.1097/AOG.0000000000003669. Accessed 2 Nov 2020.

30. Bergal A, Loucif L, Benouareth DE, Bentorki AA, Abat C, Rolain JM. Molecular epidemiology and distribution of serotypes, genotypes, and antibiotic resistance genes of Streptococcus agalactiae clinical isolates from Guelma, Algeria and Marseille, France. Eur J Clin Microbiol Infect Dis. 2015;34(12): 2339-2348. https://doi.org/10.1007/s10096-015-2487-6. Accessed 2 Sept 2020.

31. Dutra VG, Alves VMN, Olendzki AN, Dias CAG, de Bastos AFA, Santos GO, et al. Streptococcus agalactiae in Brazil: Serotype distribution, virulence determinants and antimicrobial susceptibility. BMC Infect Dis. 2014;14(1):1-9. https://doi.org/10.1186/1471-2334-14-323. Accessed 2 Nov 2020.

32. Hays C, Louis M, Plainvert C, Dmytruk N, Touak G, Trieu-Cuot P, et al. Changing Epidemiology of Group B Streptococcus Susceptibility to Fluoroquinolones and Aminoglycosides in France. Antimicrob Agents Chemother. 2016;60(12):7424-7430. https://doi.org/10.1128/AAC.01374-16. Accessed 2 Nov 2020.

33. Wang P, Tong JJ, Ma XH, Song FL, Fan L, Guo CM, et al. Serotypes, antibiotic susceptibilities, and multi-locus sequence type profiles of Streptococcus agalactiae isolates circulating in Beijing, China. PLoS
One. 2015;10(3):1-13. https://doi.org/10.1371/journal.pone.0120035. Accessed 28 Mar 2020.

\section{Publisher's Note}

Springer Nature remains neutral with regard to jurisdictional claims in published maps and institutional affiliations.
Ready to submit your research? Choose BMC and benefit from:

- fast, convenient online submission

- thorough peer review by experienced researchers in your field

- rapid publication on acceptance

- support for research data, including large and complex data types

- gold Open Access which fosters wider collaboration and increased citations

- maximum visibility for your research: over $100 \mathrm{M}$ website views per year

At BMC, research is always in progress.

Learn more biomedcentral.com/submissions 